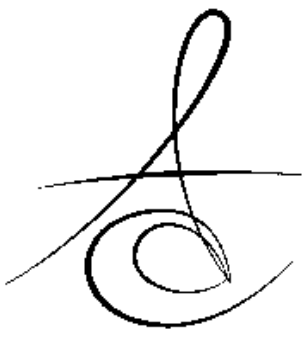

\title{
RADYOGRAFİK OLARAK ODONTOJENİK TÜMÖRÜ TAKLİT EDEN SİNÜS MUKOSELI VE SİNÜS LİTE HAZIRLIK PROSEDÜRÜ: OLGU SUNUMU ${ }^{*}$
}

\section{A SINUS MUCOCEL RADIOGRAPHICALLY MIMICKING AN ODONTOGENIC NEOPLASM AND PREPARATION OF SINUS LIFT PROCEDURE: CASE REPORT ${ }^{\star}$}

\author{
Dr. Öğr. Üyesi Nazan KOÇAK*
}

Prof. Dr. Pelin GÜNERí ${ }^{*}$

\author{
Prof. Dr. Uğur TEKİN**
}

Makale Kodu/Article code: 2923

Makale Gönderilme tarihi: 11.07.2016

Kabul Tarihi: 27.09.2016

\section{öz}

Paranazal sinüs mukoselleri, sinüs ostiumunda tıkanmaya bağlı olarak oluşan, benign, içi mukusla dolu, kistik ve yavaş büyüyen lezyonlardır. En sık frontal ve etmoidal sinüslerde, nadiren de maksiller ve sfenoid sinüslerde görülmektedir. Mukosel olguları Caldwell-Luc operasyonu veya endoskopik sinüs cerrahisi ile tedavi edilebilmektedir. Atrofik üst çenelere, sinüs lift prosedürü ile implant planlandığında, maksiller sinüs mukoselinin preoperatif dönemde tedavi edilmesi komplikasyonların oluşumunu engellemesi bakımından önem taşımaktadır. Dental Volumetrik Tomografi (DVT) lezyonun sınılarının belirlenmesinde ve preoperatif alanın özelliklerinin değerlendirilmesinde kullanılan önemli bir tanısal araçtır. Bu olguda, restoratif ve protetik tedavilerinin yapılması amacıyla kliniğimize başvuran 43 yaşındaki bayan hastanın panoramik radyografi ve dental volumetrik tomografi (DVT) değerlendirmeleri sonucunda, sol maksiller sinüs bölgesinde mukosel olduğu tespit edilmiştir. Patolojinin ayırıcı tanısı, cerrahi tedavisi ve postoperatif takip sonuçlarına da yer verilmiştir. Mukoselin ayırıcı tanısının yapılmasında DVT'nin önemli bir tanısal araç olduğu vurgulanmıştır. Ayrıca, bu olguyla, rutin cerrahi yöntemlerden farklı, modifiye cerrahi yaklaşım olan endolüminal sıvı boşaltılması tekniği ile sinüs lift işlemlerine hazırlık önerilmektedir. Araştırıcılar yeni önerilen tekniğin, cerrahi morbidite sayısının azalmasına izin verdiğini, yöntemin güvenli ve ön görülebilir olduğunu düşünmektedirler.

Anahtar Kelimeler: Maksiler sinüs, mukosel, sinüs taban yükseltmesi

\section{ABSTRACT}

Paranasal sinus mucoceles are benign, mucus-filled, cystic and slow-growing lesions that develop due to occlusion in the sinus ostium. It is mostly observed in frontal and ethmoidal sinuses, rarely in maxillary and sphenoid sinuses. Mucoceles can be treated with Caldwell-Luc operation or endoscopic sinus surgery. In the atrophic upper jaws when the implant is planned with sinus lift procedure, preoperative treatment of maxillary sinus mucoceles is important in preventing complications. Dental Volumetric Tomography (DVT) is an important diagnostic tool which in the determination of lesion margins and used to evaluate the characteristics of preoperative area. In this case, a 43-year-old female patient who referred to our clinic for restorative and prosthetic treatment was found to have mucocele in the left maxillary sinus area as a result of panoramic radiography and dental volumetric tomography (DVT) evaluations.

Differential diagnosis of the pathology, surgical treatment and postoperative follow-up results are also described. It was emphasized that DVT is an important diagnostic tool in the diagnosis of mucocele differential. In addition, it is suggested that sinus lift procedures should be prepared by, endoluminal fluid draining technique, which is a different, modified surgical approach than routine surgical methods with this case.

The observers considered that the new proposed technique allowed the reduction of the surgical morbidity and also this technique safe and predictable. Keywords: Maxillary sinüs, mucocele, sinus floor augmentation

\footnotetext{
*Ege Üniversitesi Diş Hekimliği Fakültesi, Ağız, Diş ve Çene Radyolojisi AD, İzmir, Türkiye

${ }^{* *}$ Ege Üniversitesi Diş Hekimliği Fakültesi, Ağız, Diş ve Çene AD, İzmir, Türkiye

* Oral Diagnoz ve Maksillofasiyal Radyoloji Derneği 6. Ulusal Sempozyum Ve 1. Uluslararası Kongre, 17-19 Nisan 2015,

Izmir, Türkiye'de poster bildirisi olarak sunulmuştur
} 


\section{GİRIŞ}

Paranazal sinüslerin kistleri patogenezlerine göre retansiyon kisti, mukosel ve antral psödokist olmak üzere üçe ayrılmaktadır ve bunların arasında en sık görüleni ise retansiyon kistleridir. Mukoseller, kist gibi lokal genişleme gösteren, içi mukusla dolu, yalancı çok katlı silli silindirik epitel ile çevrilidir. ${ }^{1-3}$

Patogenezlerinde ilgili maksilofasiyal bölgede travma, uzun süreli kronik inflamasyonlar, geçirilmiş cerrahiler, tümoral patolojiler, mukozanın kistik dejenerasyonu, alerjik mukozal kalınlaşma ve müköz içerikli tükrük bezlerinde tıkanmanın rol oynadığı belirtilmektedir. Ayrıca sinüsün ön ve arka duvarları arasında oluşan ve normal drenajı bozan fibrotik bantların varlığınında mukosel oluşum mekanizmasında yer aldığı belirtilmektedir. ${ }^{3-6}$ Mukosel, çocuklarda oldukça nadir olarak görülmekte ve çoğunlukla kistik fibrozisli olgularda oluştuğu bildirilmektedir. ${ }^{4}$

Diş hekimliğinde maksiller sinüs mukoselinin preoperatif dönemde görüntülenmesi, cerrahi işlemin başarısında önem taşımaktadır. Kimi araştırıcılar maksiller sinüs mukoselinin sinüs lift cerrahisine kontrendike olduğunu belirtirken ${ }^{7}$, diğerleri ise sinüs greftleme işleminde bile etkili olmadığını bildirmişlerdir. ${ }^{8} \mathrm{Bu}$ olguda, geleneksel yöntemlerden oldukça farklı bir cerrahi yöntemle tedavi edilen maksiller sinüs mukosel olgusu sunulmaktadır.

\section{OLGU SUNUMU}

43 yaşında sistemik olarak sağlıklı bayan hasta, restoratif ve protetik tedavilerinin yapılması isteğiyle 16.12.2014 tarihinde kliniğimize başvurdu. Hastanın panoramik incelemesinde olguya üst molar dişlerle ilişkili kalsifiye odontojenik tümör, ön tanısı konuldu (Resim 1). Bölge ayrıntılı olarak, 3 boyutlu değerlendirildiğinde maksiller sinüse ait mukozal kalınlaşma olduğu tespit edildi (Resim 2). Hastanın fiziksel muayenesinde intraoral-ekstraoral şişlik, palpasyonda ağrı, hissizlik veya yüzde asimetri bulgularına rastlanmadı. Hastada daha öncesinde geçirilmiş nazal cerrahi, sinüs cerrahisi veya akutkronik sinüzit hikayesi bulunmamaktaydı. DVT değerlendirmesi Planmeca Pro Max 3D DVT sistemi (Planmeca, Helsinki, Finlandiya), $4 \times 5 \mathrm{~cm}$ görüntüleme alanı, $150 \mu \mathrm{m}$ izotropik voksel boyutu, özelliklerine sahip cihaz kullanılarak elde edilmiştir. Hastadan alınan dental volumetrik tomografi görüntüsü, $90 \mathrm{kVp}$ ve $9 \mathrm{~mA}$ 'da, sagittal düzlem yere dik, Frankfurt horizontal düzlem yere paralel konumlandırılarak alındı.

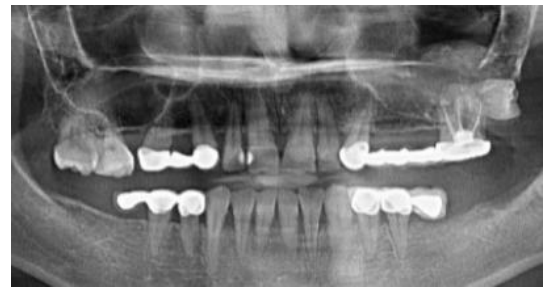

Resim 1. Olgunun preoperatif panoramik radyografisi

Elde edilen DVT görüntüsünde çekilmiş sol 1.molar diş bölgesinde, sinüs içerisinde kanal dolgu patına benzer yabancı cisme ait radyoopasiteye rastlandı. Mukosele spesifik kubbe şeklinde bu görüntü aksiyel, sagital, koronal kesitler üzerinde izlenmektedir. Mukozal kalınlaşma miktarı (18 mm x27 $\mathrm{mm} \times 18 \mathrm{~mm}$ ) olarak belirlenmiştir (Resim 2).

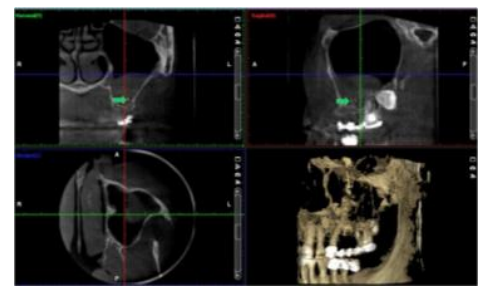

Resim 2. Mukoselin ve yabancı cismin lokalizasyonunu gösteren olgunun preoperatif DVT görüntüsü

Hasta protetik rehabilitasyon amacıyla başvurduğundan, bölgenin sağlıklı hale getirilmesi ve implant yerleştirmeye hazırlıkı olması gerekmektedir. Hastada bulunan kanal tedavili sol 2.molar diş ve gömülü sol 3.molar dişlerin lezyonun etiyolojisinde rol aldığı düşünüldüğünden cerrahi olarak alınmalarına, mukoselin sinüsten uzaklaştırılmasına ve ardından bölgeye implant yerleştirilmesine karar verildi. Maksiller sinüse lateralden açılan pencere ile mukoselin yansıması izlenmekte ve erişimi mümkün hale gelmektedir (Resim 3). Ardından mukozal kiste doğrudan erişime izin veren, neoformasyon bulunan sıvıyı dışarı çıkarmak için bir şırınga veya suction ile sıvının çekilmesi işlemi gerçekleştirilmiştir. Sıvının çekilmesi lezyonun içindeki internal basıncı

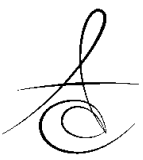


azaltmaktadır. Boyutu küçülen lezyon, sinüs lift cerrahisi sırasında sinüs membranına zarar verme riskini azaltmaktadır (Resim 4).

Enfeksiyonun tekrar gelişme riski olduğundan takip sonrası kontrolü uygun görülüp, kontrol sonrası sinüs lift cerrahisinin randevu verilmesine karar verildi. Postoperatif 2. ay panoramik görüntüsü (Resim 5) ve 10.ay DVT görüntüsü (Resim 6) şekildeki gibidir. Operasyon sırasında histopatolojik değerlendirme için alınan biyopsi örneğinde kist epiteli tanımlanmış olup, DVT' de izlenen görüntünün, mukosel görünümünü desteklediği düşünülmektedir.

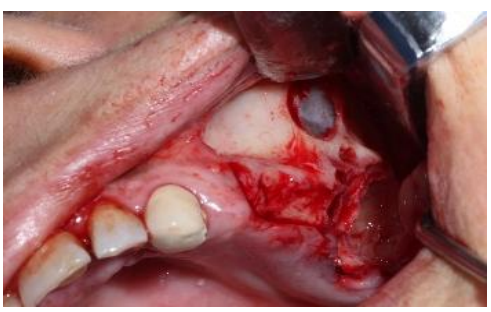

Resim 3. Maksiller sinüse açılan lateral pencereden mukosele ait kistik sıvının yansıması

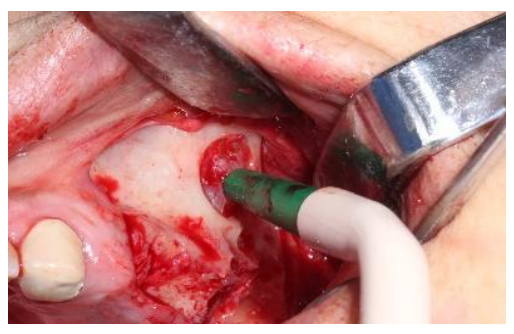

Resim 4. Operasyon sırasında mukoselin suction ile alınması

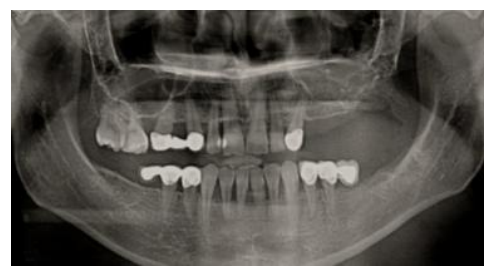

Resim 5. Olgunun postoperatif 2.ay panoramik radyografisi

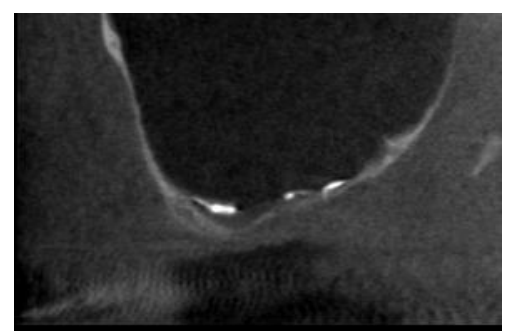

Resim 6. Olgunun postoperatif 10.ay DVT görüntüsü

\section{TARTIŞMA}

Maksiller sinüs mukoseli genellikle nadir görülen, yavaş büyüyen ve klinik olarak iyi huylu gelişim gösteren bir patolojidir. ${ }^{5}$ Çoğunlukla hastaların daha önce geçirilmiş sinüs cerrahisi öyküsü bulunmaktadır. ${ }^{9}$ Ancak sunulan olguda geçirilmiş bir sinonazal cerrahi veya travma öyküsü alınmamıştır. Postoperatif dönemde, uzun yıllar sonra maksiller sinüsün lateral duvarında oluşan yapışıklıkların da mukus drenajını engellediği düşünülmektedir ${ }^{3-6}$ ve sinonazal cerrahi veya travma öyküsü olmayan bazı olgularda da maksiller sinüs içinde bulunan septaların mukus drenajını bozarak mukosel oluşumuna yol açabilecekleri belirtilmiştir. ${ }^{9}$ Ancak sunulan olguda, bu olası faktörlerin dışında, etiyolojik faktörün yabancı cisim reaksiyonu olduğu ve buna bağlı mukosel geliştiği düşünülmektedir.

Mukosel ile ilgili bulgular ve semptomlar, lezyonun lokalizasyonuna ve kemik erozyonunun büyüklüğüne bağlı olarak değişmektedir. Nazal obstrüksiyon, epifora, dental komplikasyonlar gibi hafif semptomlardan, ekzoftalmus, proptozis, diplopi ve görme bozukluğu gibi ağır semptomlara kadar değişiklik gösterir. Mukoseller maksiller sinüs ön duvarını erode ederek yanakta şişlik ve yüzde asimetriye yol açabilmeleri dışında, kranyuma ulaşarak bununla ilgili semptom ve bulgularla da ortaya çıkabilirler.,6 Diğer taraftan mukosel tedavi edilmeksizin yapılan maksiller sinüs lift operasyonu sonrasında postoperatif sinüzit ve kemik greftlerinin enfeksiyonu gibi çok ciddi komplikasyonlar da gelişebilmektedir. Ancak sunulan olguda mukosel çok büyük boyutlara ulaşmadan tedavi edildiğinden belirgin semptomlar da eşlik etmemiştir.

Preoperatif tanıda, lezyonun sınırlarının belirlenmesinde, 3 boyutlu görüntüleme önemli yer tutar. Homojen opasifikasyonla dolmuş olan ve genişlemiş sinüs kavitesini gösteren BT veya DVT görüntüsü, mukosel için diagnostiktir. ${ }^{10}$ Ancak maksiller sinüs hastalıklarının teşhisinde ilk olarak, genellikle Waters sinüs projeksiyonu tercih edilmektedir. Literatürde bulunan bir çalışmada, paranazal sinüslerin radyolojik olarak incelenmesinde, öncelikle standart direkt grafilerin kullanılması gerektiği, pozisyonlandırmadaki zorluk, anatomik yapıların süperpoze olması, yumuşak dokularda meydana gelen patolojiler ve kemik destrüksiyonlarını tespit etmedeki yetersizlik gibi dez- 
avantajlardan dolayı üç boyutlu görüntüleme yöntemlerinin kullanılabileceği vurgulanmıştır. ${ }^{11}$ Günümüzde, bu nedenlerle BT ve DVT konvansiyonel radyografilerin yerini almıştır. DVT, maksillofasiyal bölge sert dokularının ayrıntıı görüntülenmesi için üretilmiştir. DVT de konvansiyonel BT'lere kıyasla radyasyon dozu ve maliyet çok daha azdır. Yüksek diagnostik kalite, yüksek çözünürlük, minimal distorsiyonla üç boyutlu görüntüleme sağlaması, bu yönteminin kullanılabilirliğini artırmışır. ${ }^{11}$

Klinik muayene, radyolojik görüntüleme ve cerrahi müdahale ile mukoselin tanısı konulmaktadır. Mukoselin ayırıc tanısının yapılması zordur ve tedavi planlamasında bu kritik önem taşımaktadır. Mukoselin ayıııcı tanısı çoğunlukla BT $^{\prime}$ deki bulgular ile belirlenmektedir ve üç boyutlu görüntüleme yöntemi diğer yöntemlere göre daha çok avantaj sağlamaktadır. Mukosel $\mathrm{BT}^{\prime}$ de hipodens, kontrast tutulumu olmayan, sinüs kavitesini dolduran ve ekspansiyon yapan kitle olarak tanımlanmaktadır. ${ }^{12}$ Sunulan olgunun DVT görüntüsünde, sol maksiller sinüsü kısmen dolduran, kistik lezyon olarak izlenmiştir. Yaygın kemik yıkımı varlı̆ında malign tümörlerle, kemik yıkımı eşlik etmediğinde ise; retansiyon kistleri, sinüzit, ve geniş paranazal sinüs polipleri ile ayırıcı tanısı yapılmalıdır. ${ }^{4,12}$ Ayrıca mukoseller; nörofibromlar, dermoid ve epidermoid kistler, sementifying fibromlar, silindromalar, inverted papillomalar ve anjiyofibromlar gibi sinus duvarında ekspansiyona yol açan lezyonlarla da radyolojik olarak ayırıcı tanısı yapılmalıdır. ${ }^{5,6}$

Maksiller sinüs mukoselleri; Caldwell-Luc, inferior meatal antrostomi ve lateral rinotomi operasyonlarıyla tedavi edilebilmektedir. ${ }^{4,6}$ Son yıllarda etmoid, frontal ve maksiller sinüs mukoselleri için endoskopik girişimler de uygulanmaktadır. ${ }^{6}$ Böylece rekürrens ve komplikasyon oluşma ihtimali de azalmaktadır. ${ }^{13}$ Mukoselin kemik yıkımına neden olarak yumuşak doku ve orbitaya doğru ilerlediği olgularda açık cerrahi girişime başvurulmaktadır. ${ }^{14}$ Sunulan olgu ile benzer şekilde modifiye cerrahi yöntemi kullanan tek çalışmada, sunulan olgudan farklı olarak aynı seansta greftleme ve implant yerleştirilmesi yapılmıştır. ${ }^{15}$ Ancak sunulan olguda yeterli miktarda kemik bulunmadığından ve mukoselin rekürens takibinin yapılması açısından aynı seansta greftleme ve implant yerleştirilmesi işlemleri yapılmamıştır.

Maksiller sinüste yabancı cisim bulunmasına rağ- men mukoselde takip süresi boyunca rekürens görülmemiştir. Modifiye cerrahi yaklaşımla endolüminal SIVı boşaltııması tekniğinin güvenli ve ön görülebilir bir teknik olması cerrahi komplikasyon gelişimine engel olmaktadır.

\section{SONUÇ}

Maksiller sinüste mukosel varlığının, sinüs lift cerrahisine kontrendikasyon oluşturmadığı ve DVT ile preoperatif değerlendirmenin gereksiz komplikasyonların oluşumunu engellediği düşünülmektedir. ${ }^{15}$ Ayrıca kullanılan modifiye cerrahi yöntemin operasyonu güvenli hale getirerek membran perforasyonuna engel olduğu ve takip süresince mukoselde rekürensin görülmemesiyle de güvenli bir yöntem olduğu düşünülmektedir.

\section{TEŞEKKÜR VE ANMA}

Olgumuza gönüllü olarak katılan Ege Üniversitesi Diş Hekimliği Fakültesi hastasına içtenlikle teşekkür ederiz. Çıkar çatışması: Yazarlar bu çalışmayla ilgili herhangi bir çıkar çatışmalarının bulunmadığını bildirmiş/erdir.

Nazan Koçak: ORCID ID: 0000-0002-3717-2098

Pelin Güneri: ORCID ID: 0000-0001-9423-9191

Uğur Tekin: ORCID ID: 0000-0003-0008-1333

\section{KAYNAKLAR}

1. Ballenger JJ, Snow JB. Otolaryngol Head Neck Surg. 15th ed. Baltimore; Williams\&Wilkins: 1996. p.7

2. Meral G, Aktaş A, Taşar F, Yıldırım B, Günhan Ö. Maksiller sinüs mukoselinin cerrahi tedavisi. Hacettepe Üniv Diş Hek Fak Derg 2008;32:51-5.

3. Som PM, Curtin HD. Head and Neck Imaging. 4th ed. St Louis; CVMosby: 2003. p.193-260.

4. Skoulakis CE, Velegrakis GA, Doxas PG, Papadakis CE, Bizakis JG, Helidonis ES. Mucocele of the maxillary antrum in an eight-year-old boy. Int J Pediatr Otorhinolaryngol 1999;47:283-7.

5. Jayaraj SM, Patel SK, Ghufoor K, Frosh AC. Mucoceles of the maxillary sinus. Int J Clin Pract 1999;53:391-3.

6. Özcan M, Akdoğan Ö, Gün T. Giant mucocele of the maxillary antrum: Report of a case. Türk Otolarengoloji Arşivi 2002;40:15.

7. Jensen OT, Shulman LB, Block MS, Lacono VJ. Report of the Sinus Consensus Conference of 1996. Int J Oral Maxillofac Implants 1998;13:1145. 
8. Mardinger O, Manor I, Mijiritsky E, Hirshberg A. Maxillary sinus augmentation in the presence of antral pseudocyst: a clinical approach. Oral Surg Oral Med Oral Pathol Oral Radiol Endod 2007;103:180-4.

9. Sharp JF. Non-axial proptosis without diplopia secondary to maxillary pyomucocele. J R Soc Med 1989;82:506-7.

10. Sümbüllü MA. Maksiller Sinüs Enflamatuar Hastalıklarında Volumetrik Dental Tomografinin Tanı Değeri ve Bulguların Waters Pozisyonunda Çekilen Paranasal Sinüs Radyogramı ile Karşılaştırılması. Sağlık Bilimleri Enstitüsü, Oral Diagnoz ve Radyoloji Anabilim Dalı. Doktora Tezi: Atatürk Üniv. Diş. Hek. Fak. 2010 Erzurum.

11. Çakur B, Sümbüllü $M A$, Antral retansiyon kistinin radyolojik tespiti; Dental volümetrik tomografi ile waters pozisyonunda çekilen paranazal sinüs radyogramın karşılaştırılması. Atatürk Üniv Diş Hek Fak Derg 2011;21:63-7.

12. Mafee M.F. Computed tomography, magnetic resonance, in: J.J. Ballenger, B.J. Snow (Eds.), Otolaryngol Head Neck Surg. 15th ed. Baltimore; Williams\& Wilkins: 1996. p. 715-6.

13. Uysal İÖ, Yüce $S$, Köşger HH, Müderris S. Maksiller Sinüs Mukoseli: Olgu Sunumu. KBB ve BBC Dergisi 2003;11:77-80.

14. Çaylakli F, Yavuz H, Cagici AC, Ozluoglu LN. Endoscopic sinus surgery for maxillary sinus mucoceles. Head Face Med 2006;2:29.

15. Maiorana $C$, Beretta $M$, Benigni $M$, Cicciù $M$, Stoffella $E$, Grossi GB. Sinus lift procedure in presence of mucosal cyst: a clinical prospective study. J Implant Adv Clin Dentistry 2012;4:53-60.

\section{Yazışma Adresi}

Dr. Öğr. Üyesi Nazan KOÇAK, Mersin Üniversitesi Diş Hek. Fak. Ağız-Diş ve Çene Radyolojisi A.D Yenişehir/ MERSİN

Tel: 05458297898

e-mail: nazannkocak@gmail.com 